\title{
Research on the Development of Professional Quality of College English Teachers in Internet+ Environment
}

\author{
Wang Ying \\ Jilin Business and Technology College \\ 182076127@qq.com
}

Keywords: College English Teachers, Professional Quality, Internet+ Environment

\begin{abstract}
The development of network technology has caused great changes in the practice of college English teaching, and put forward higher requirements for the professional quality of college English teachers. This paper discusses the professional quality of college English teachers from the aspects of teaching idea, professional spirit, network knowledge and skills, information management, integration ability, teaching and research consciousness and ability, and discusses the development of professional quality of college English teachers in internet+ environment.
\end{abstract}

\section{Introduction}

The rapid development of computer and network technology has had a great impact on college English teaching, which has led to the reform of college English teaching mode, teaching methods and means, autonomous learning and so on, and also put forward higher quality of college English teachers' professional quality Requirements, greater challenges \# College English teacher is the main body of the implementation of college English teaching reform, its professional quality is the impact of teaching reform, teaching quality, curriculum construction and development of key factors in recent years, some domestic scholars on the impact of college English teachers professional development The investigation of the status quo of college English teaching in colleges and universities found that college English teachers bear the workload of overloading, the number of class classes taught, the opportunity to improve the training is relatively small, These factors affect the quality of teaching, is not conducive to the improvement of teachers' scientific research ability, and thus does not contribute to the development of professional quality. Based on a case study, Zhang Lian found that the main factors restricting the professional development of English teachers in colleges and universities include: heavy workload, poor professional development conditions, lack of knowledge and scientific research methods. The study of the professional development environment of English teachers in colleges and universities found that the interaction of individuals, schools and social and cultural environment in Chinese college English teachers led them to face the complicated and difficult professional development environment. The main restrictive factors in the personal environment are Teachers' own development needs and the external environment between the contradictions in the school environment, the main constraints are administrative tendencies, professional support for the lack of unreasonable evaluation system, the social and cultural environment in the main constraints of the educational system, traditional culture, family Responsibility, utilitarian oriented and so on. The results of the above survey show that the development of the professional quality of college English teachers is influenced by many factors, both internal factors and external factors. Only by take a number of factors to study the professional quality of college English teachers in order to make a real benefit to college English teachers The Effective Strategy of Professional Quality Development.

\section{Changes in College English Teaching under the Internet+ Environment}

The rapid development of modern network technology, led to the college English teaching environment, goals, patterns, means, time and space and the role of teachers and a series of changes. The development of network technology to the teaching environment from the traditional fixed blackboard and chalk into a set of sound, images, text in one form of flexible and diverse 
multimedia, network, virtual teaching space. The development of network technology is to teaching objectives from the traditional knowledge to teach and explain to the practical application of ability to enhance and cultural literacy training. The development of network technology has made great changes in teaching methods. In the past, teacher-centered, by the teacher's pronunciation and teaching as the main teaching means to influence students' learning passion. It replaced by audio-visual aids and fusion of sound, images, writing PowerPoint, Flash and other courseware form. The development of network technology has made great changes in teachers' teaching time and space. In traditional teaching, the teacher's teaching activities are basically fixed in the designated classroom and are limited to a limited time. The development of modern technology, so that the teaching space of teachers has been greatly expanded, teaching time has also been extended. In addition to teachers to master the classroom, the classroom also need to E-mail, MSN, QQ network and mobile QQ and other tools to answer students' problems. The development of network technology is to the role of teachers to diversify. Teachers are no longer the protagonists of the classroom, and transformers into the classroom learning process with the resources of the designers and developers of students to collaborate with the organizers and collaborators of the student learning process of the guide, facilitator, monitor and assessor. The change of college English teaching caused by network technology puts forward higher requirements for the professional quality of college English teachers.

College English teaching reform is inseparable from the teacher's action participation. With the development of the information society, the progress of the level of students and teachers only constantly updated their professional knowledge, and constantly improve their professional development to stand firm three feet podium. In the face of a full range of national college English teaching reform, teachers are faced with teaching requirements, student level, teachers' teaching assessment standards to increase the pressure and challenges brought by \$. However, the majority of experts and scholars found that the current college English teachers in China there are serious problems, specifically in: unreasonable academic structure, interdisciplinary knowledge is not comprehensive; workload, ignore the theoretical level of improvement; scientific research ability is weak, lack of scientific research spirit; Self-learning and psychological development psychological motivation, lack of professional sense of crisis. The improvement of college English teaching quality, the success of reform and the development of disciplines all need a high - quality and high level teachers, and the development and perfection of college English teachers are imminent.

Teachers should be based on their own situation to customize scientific and rational professional development goals, the overall thinking of college English teaching reform for the professional development of teachers pointed out the direction of "excellent foreign language teachers in addition to qualified foreign language teaching ability, Knowledge of educational knowledge, but also It is necessary to have the correct view of the concept of ethics, Foreign language teaching, but also have the right learning and development concept. "College English teachers must have excellent basic skills in English, keep up with the development of linguistic theory; understanding of Chinese and Western culture, Penetrate into teaching; master modern educational technology, skilled use of multimedia and other computer-aided teaching methods; constantly updated teaching philosophy, adjust the role of teachers and actively innovative teaching methods.

Table 1 China Journal Network nearly five years Statistics on the Development of College

English Teachers' Professional Qualities

\begin{tabular}{|l|l|l|l|l|}
\hline & 2006 & 2007 & 2008 & 2009 \\
\hline $\begin{array}{l}\text { College Teacher major and } \\
\text { develop directions }\end{array}$ & 2 & 7 & 15 & 20 \\
\hline
\end{tabular}

Teachers' professional development refers to the teachers in the professional quality of the continuous growth and the pursuit of mature process. Under the guidance of the idea of lifelong education, according to the different stages of teacher development, the teacher's pre-service training, after-service training and on-the-job training and so on overall consideration, the overall design, including the establishment of pre-professional teachers, professional counseling, Professional to improve the integration of teachers professional development system. Teachers 
professional development is a continuous development process, teachers continue to grow, continue to accept new knowledge, the process of growing professional ability. Teachers not only to accept the training of classroom skills, but also to carry out the application of pragmatic language testing and evaluation, research methods and other theoretical courses to enable teachers from the theoretical height to understand and grasp the practice of language classroom. The professional development of teachers should be studied from four aspects: professional knowledge, professional ability, educational concept and professional attitude. The professional development of college English teachers should include the continuous updating of professional knowledge, the continuous improvement of professional ability, the deepening of professional idea and professional attitude the continuous improvement.

\section{College English Teachers Need to have the Professional Quality}

The teaching idea directly determines the teacher's teaching behavior and the teaching way. With the development of network technology and the development of quality education, teachers need to change the traditional "teacher-centered, classroom-centered, knowledge-based teaching as the main content" teaching concept. The openness, interactivity, fictitiousness, freedom, equality and so on of the network and the increasingly strong modern consciousness of modern college students require teachers to fully respect students' sense of autonomy, thus forming "student-centered, computer As the center, to learn ways to guide and learning resources as the main content "teaching philosophy. This requires college English teachers in the teaching process of flexible use of humanism theory, construction theory and social interaction theory in line with contemporary student characteristics and technical characteristics of the educational philosophy. Humanistic theory emphasizes the study of true personal meaning. The constructive theory emphasizes the construction process of teachers' personal meaning to help and promote the language learners. Social interaction theory emphasizes that human learning and development take place in the interaction and interaction between people. Under the condition of the development of network technology, the implementation of these educational theories can fully cultivate the modern spirit, modern accomplishment and comprehensive ability of contemporary college students. To this end, college English teachers need to constantly change their teaching philosophy, keep up with the pace of technological development of the times, to cultivate modern society needs modern talent.

Have a stronger sense of responsibility and love. The extension of teaching time brought about by the network technology and the continuity of college English learning make it possible for many English learners to use non-fixed learning places and flexible learning time outside the classroom to ask teachers to ask questions and problems in many ways, to increase the opportunity to communicate with teachers. This requires college English teachers to have the spirit of dedication, to cultivate their own stronger sense of responsibility and love, in the spare time patience through the network to answer students' questions and problems, equality, in good faith and students in-depth exchanges.

Have the network information management ability. This mainly refers to a keen sense of network information, improve information management capabilities and adhere to the network ethics and ethics. With a keen sense of network information is to fully understand the importance of network information and important significance, to develop their information on the sensitivity and insight. Improving the ability to manage information refers to the ability to continuously improve access to, evaluate, publish, utilize and create network information. Adhere to the network ethical principles refers to the face of complex network information environment, we should have a moral, ethical, emotional, legal awareness, consciously abide by the relevant guidelines, consciously bear the relevant social responsibility. As a designer and developer of college English learning process and learning resources, college English teachers need to continuously improve their network information management ability, and constantly design, develop and introduce valuable and meaningful students' healthy growth Resources. This is of great significance to promote the reform of college English teaching and realize the sustainable development of college English teachers' professional development. 


\section{Study on the Ways of Cultivating College English Teachers' Professional Qualities under the Internet+ Environment}

The concept of teacher education mainly includes three stages: teacher training, teacher education and teacher development. College English teacher training mainly refers to the training of teachers in teaching skills. College English teacher education is based on the teachers to master the basic teaching skills on the basis of further strengthening the teacher's linguistics, language testing and evaluation, literature, psychology, education, scientific research methods and other aspects of comprehensive education and comprehensive quality improvement Improve the teacher 's theoretical consciousness. The development of college English teachers emphasizes on the basis of teacher education, encourages and guides teachers to constantly reflect on their own teaching, constantly observe and summarize their own teaching process, constantly evaluate their teaching effect, and actively carry out theoretical research on English teaching behavior.

Based on the concept of teacher education, in the internet+ environment, we can from the following aspects to explore the development of college English teachers professional quality.

Education managers need to truly change the concept of education management, from the fundamental understanding of the development of network technology to bring profound changes in education and far-reaching impact. Only education managers really change the concept of education management, it may really pay attention to the development of professional quality of teachers, it may provide financial support for these developments and create a good environment.

College English teachers themselves to really change the concept of teaching and truly aware of the need to further enhance their professional quality and urgency. Only by changing the concept, college English teachers will really act.

Make full use of the network of openness, equality and interaction and other characteristics of teaching exchanges and research cooperation. College English teachers can make full use of the global college English teacher resources, through the network to actively carry out inter-school, regional, virtual community teaching exchange and cooperation teaching and research, so as to continuously enhance their research awareness and research ability.

Conduct continuous teacher training. School training is one of the effective ways to improve the professional quality of teachers. The effectiveness of school training is that it can focus on the training of teachers in the teaching of practical problems. This training is conducive to teachers to give full play to their main sense. Therefore, the school needs to regularly train teachers on the modern teaching concept, computer and network knowledge, information management knowledge, scientific research methods, moral literacy and other aspects of training, but also from time to time on the outstanding problems of teachers training, and constantly improve the teachers Quality and ability.

And establish a practical evaluation system of teachers' network teaching ability. The establishment of the evaluation system will effectively promote the teachers to consciously combine their own actual situation to continuously strengthen the internet + environment, teaching methods, content, process, model and the role of teachers to explore, practice and research, and thus continue to develop their own professional quality.

The establishment of incentive mechanism is to stimulate teachers in the internet+ environment for teaching practice and research enthusiasm and create a good atmosphere for research. Attractive incentives will be active teachers to practice and research ideas.

The so-called teaching action research refers to the teachers in the teaching process, their own teaching ideas, the use of teaching methods and the resulting teaching effect of reflection, in the reflection to re-examine their own teaching concepts, explore, research and improve teaching methods, In order to achieve further improve the teaching effect and update the teaching concept of purpose. Action research mainly includes identifying research questions, proposing hypotheses and re-identifying problems through investigation and research, developing action plans through relevant literature research and communicating with other teachers, implementing plans, observing and collecting data analysis, reflecting and evaluating action effects, the question is ready for the next round of action research. Action research combines teaching theory with teaching practice. 
Through the action research, teachers can consciously study and explore their own teaching behavior under the guidance of the theory, which can directly help solve the problems in their teaching and help to improve the teachers' scientific research ability. Action research has a great effect on improving the quality of teaching and promoting the professional development of college English teachers.

American psychologist Posner put forward the teacher's growth formula: growth = experience + reflection. China's educator Professor Ye Lan pointed out: a teacher to write a lifetime lesson plan is not necessarily a teacher, if a teacher to write many years of reflection is likely to become a teacher. Reflective Teaching is an Effective Way to Promote the Development of Foreign Language Teachers. Because teachers in the process of reflection, you can continue to optimize and improve their own teaching ideas, methods and strategies to deepen the understanding of the law of teaching activities and understanding. After reflection, teachers' cognitive level will continue to improve, teaching experience can continue to accumulate, teaching behavior can continue to improve, effect continues to improve. In the reform environment, teachers should be based on modern teaching ideas and teaching ideas as a guide to their own teaching rational reflection, from the teaching concept, teaching methods, teaching materials and other aspects to think, question or evaluate the effectiveness of their own teaching, and conscious According to the results of reflection to correct their own bad behavior in teaching. Through this scientific and effective reflection, teachers can continue to improve their professional level. There are many ways to carry out reflective teaching in teaching practice, such as writing a teaching log, reviewing classroom video, communicating with colleagues and conducting student surveys.

\section{Conclusion}

As a key factor that directly affects the quality of college English education, the future development and professional quality of life of college English teachers can not be ignored (to improve the professional identity of college English teachers, to meet the needs of teachers' self-development, to improve their scientific research ability, not only directly The improvement of the quality of college English teaching is also related to the difficulties and problems in the development of the demand and quality of the whole college English teacher group. The actual model of self-development of English teachers is a valuable attempt to solve the fundamental problem of college English teacher training, and it is expected to fundamentally improve the comprehensive quality of college English teachers and provide a solid human resource base for college English teaching reform. And ultimately improve our students' comprehensive utilization of English ability.

\section{References}

[1] Wang Lieqin. Foreign Language Teachers' Professional Accomplishment and Its Development Obstacles and Countermeasures [J]. Education Exploration, 2009 (01)

[2] Wu Yian. Foreign language teacher professional development [J]. Foreign Language Research, 2008 (03)

[3] Guo Yubin, Zhao Jiahong. Analysis of the basic elements of foreign language teachers professional quality elements [J]. Tibet Education, 2012 (01)

[4] Yu Caifeng. English teachers professional quality research [J]. Overseas English, 2010 (10)

[5] Gao Yue, Zhang Yue, Yin Lixin. The professional development of college English teachers [J]. Education Exploration, 2009 (03)

[6] Dan Tsinghua. Improve their own quality, to meet the requirements of the times [J]. Chinese teachers, 2011 (S2) 